Original article

Section: Food Quality and Functionality

\title{
Impact of Sodium Alginate and Dried Apple Pomace Powder as a Carrier Agent on the Properties of Freeze-Dried Vegetable Snacks
}

\author{
Magdalena Karwacka*® ${ }^{\circledR}$, Martyna Gumkowska, Katarzyna Rybak ${ }^{\circledR}$, \\ Agnieszka Ciurzyńska ${ }^{\circledR}$, Monika Janowicz ${ }^{\circledR}$
}

\author{
Department of Food Engineering and Process Management, Institute of Food Science, \\ Warsaw University of Life Sciences, 159c Nowoursynowska St., 02-776, Warsaw, Poland
}

Key words: freeze-drying, vegetable snacks, sodium alginate, apple pomace, carrier agent, physicochemical properties

The food industry is committed to supplying nutritious products that are attractive and convenient for consumers. Freeze-dried fruit and vegetable snacks that exemplify such products are difficult to obtain since it is necessary to use a carrier agent (usually a hydrocolloid ingredient) which meets the requirements of a sustainable development conceptual framework. Therefore, research has been undertaken to replace such a carrier agent with food waste fruit pomace. This study compared selected physicochemical properties of freeze-dried vegetable snacks obtained through the addition of sodium alginate and dried apple pomace powder in terms of the viability of replacing hydrocolloid carrier agents in freeze-dried products with fruit pomace. Three vegetable sets containing: yellow bean, carrot and potato were prepared and modified by adding diverse carrier agents. Snacks with the addition of dried apple pomace powder featured higher dry matter content and true and apparent density, but sodium alginate-structured products were harder and more porous. Dried apple pomace powder improved the health-promoting properties of the snacks, such as total phenolic content and antioxidant capacity. The type of additive also affected the internal structure of the products. The results indicate that the application of both dried apple pomace powder and sodium alginate as carrier agents can result in snacks characterised by repeatable quality, but it is unclear whether the total replacement of hydrocolloid is sustainably efficient.

\section{INTRODUCTION}

Consumers are becoming increasingly aware of the importance of nutrition and a balanced diet as far as their health and quality of life is concerned. Although the popularity of a plant-based diet preventing civilisation diseases and environmental crisis is constantly increasing, the consumption of large amounts of highly-processed and nutrient-poor food products is regarded as an outstanding issue to be addressed for various age groups [Ciurzyńska et al., 2019a]. Because of the fast pace of life, consumers are often forced to reach for convenient and easy-to-eat products, such as healthy and unhealthy snacks that are abundant on store shelves. Although the healthy snack market is abundant with dried fruits, vegetables, nuts and cereal bars, they compete with candies and other high-energy products. It has been proven that consumer choices depend on the accessibility and visibility of products [van Kleef et al., 2012]. A major impact on the attractiveness of dried snacks is shown by their textural and sensory properties. Consumers seek a pleasurable eating experience that may be ensured by rich flavour and aroma as well as crunchiness and crispness, although many consumers also declare an interest in the nutritional values of food [Silva-Espinoza et al., 2021].

Freeze-drying is a method that preserves the structure of the products because of its mechanism (water is removed in a gas state instead of a liquid state). This phenomenon is caused by low pressure in the freeze-dryer chamber, which accounts for the process to be run at a low temperature. The pre-set parameters of food dehydration by means of freeze-drying influence both the physical and nutritional properties of products [Nowak \& Jakubczyk, 2020]. The properties of dried (especially freeze-dried) food products may be modulated by both the process parameters and by adding structure-forming agents such as hydrocolloids. This combination of hydrocolloid carrier agents and the freeze-drying method ensures structure preservation and avoids undesirable changes that may occur during thermal treatment, such as air-drying [Cassanelli et al., 2018]. There have been several studies on the use of hydrocolloids as carrier agents in the production of freeze-dried snacks, e.g. gellan gum [Cassanelli et al., 2018], pectin, xanthan gum and locust bean gum [Ciurzyńska et al., 2019b], sodium alginate [Ciurzyńska et al.,

\footnotetext{
* Corresponding Author:

E-mail: magdalena_karwacka@sggw.edu.pl (M.Sc. M. Karwacka)
} 
2020; Kuo et al., 2021], gum arabic and bamboo fibre [Silva-Espinoza et al., 2021] and many others.

It has been shown that hydrocolloids can produce innovative and attractive food products, but processes of obtaining hydrocolloids are usually complex and require significant chemical reagents, time and equipment, which cause high energy consumption [Liew et al., 2019]. According to sustainable development goals, a major challenge for agriculture and the food industry is a reduction of carbon and energy footprints, which have an adverse impact on the natural environment. Food processing optimisation and solid waste management constitute one of the ways to follow this conceptual framework [Karwacka et al., 2020]. Therefore, all over the world, scientists are conducting research into reusing food waste and by-products as innovative food products. The addition of fruit pomace as a structure and texture-forming carrier agent in dairy, meat, bakery and pastry products is becoming a major topic [Kruczek et al., 2016], but there is no research available on using pomace as a carrier agent in freeze-dried products. Fruit pomace has high nutritional and functional potential. For example, apple pomace is a rich source of polysaccharides, dietary fibre, micro- and macro-elements, as well as bioactive compounds, such as antioxidants [Skinner et al., 2018], and it displays gelation capacity and the ability to retain water [Masiarz et al., 2019].

This study compared selected physicochemical properties of freeze-dried vegetable snacks (obtained through the addition of sodium alginate and dried apple pomace powder) to investigate replacing hydrocolloid carrier agents in freeze-dried products with fruit pomace powders.

\section{MATERIAL AND METHODS}

\section{Material}

Frozen vegetables (yellow been, carrot and potato) provided by Unifreeze sp. z o.o. (Poland), dried apple pomace powder (AP) (Greenherb, Łańcut, Poland), sodium alginate (SA) (Agnex, Białystok, Poland) and calcium lactate (Agnex, Białystok, Poland) were used to prepare freeze-dried snacks.

\section{Snack preparation}

Before deploying technological processes, all products used for snack preparation were weighed in the proportions shown in Table 1. A 600-g portion of vegetables was used in one technological cycle.
Yellow bean (YB) was blanched at $85^{\circ} \mathrm{C}$ for 4 min and potato $(\mathrm{P})$ cubes $(1 \times 1 \times 1 \mathrm{~cm})$ were cooked at $100^{\circ} \mathrm{C}$ for $15 \mathrm{~min}$ using Thermomix TM5 (Vorkwerk, Wuppertal, Germany). Thermal treatment was launched when the water with vegetables reached the pre-set temperature. Carrot $(\mathrm{C})$ cubes $(1 \times 1 \times 1 \mathrm{~cm})$ were thawed at ambient temperature for about $30 \mathrm{~min}$. The vegetables, after having undergone the aforementioned treatment, were ground to varying degrees. The YB was cut in a laboratory knife mill GRINDOMIX GM 200 (Retsch, Haan, Germany) for $1 \mathrm{~min}$, applying the continuous mode and a knife speed of 4,500 rpm. The P cubes were blended into smooth puree using a hand blender (Bosch, Gerlingen, Germany). The $\mathrm{C}$ cubes were milled in a meat grinder (Zelmer, Rzeszów, Poland), using a mesh of $4 \mathrm{~mm}$ in diameter.

To produce snacks with apple pomace powder (Table 1), the pre-processed vegetables and AP were mixed with a whisk, placed into $3.5 \times 2.0 \times 10.5 \mathrm{~cm}$ silicone moulds and frozen at $-40^{\circ} \mathrm{C}$ in a shock freezer (Irinox Shock Freezer HCM 51.20, Treviso, Italy). The addition of AP to the vegetables in the amount of $2 \mathrm{~g} / 100 \mathrm{~g}$ maintained an appropriate structure and did not change the organoleptic features of the snacks developed in preliminary studies. To produce snacks with sodium alginate, SA was added to the pre-processed vegetables and whisked using a manual blender. After measuring the specific volume of water containing calcium lactate, it was heated up to $40^{\circ} \mathrm{C}$ until the salt dissolved. This solution was then poured into the vegetables and whisked again to be put into $3.5 \times 2.0 \times 10.5 \mathrm{~cm}$ silicone moulds and frozen at $-40^{\circ} \mathrm{C}$. After freezing the snacks, they were put into a Gamma 1-16 LSCplus freeze-dryer (Martin Christ Gefriertrocknungsanlagen $\mathrm{GmbH}$, Osterode, Harz, Germany) and dried for about $48 \mathrm{~h}$ at a shelf temperature of $30^{\circ} \mathrm{C}$ and a pressure of $63 \mathrm{~Pa}$. Freeze-dried snacks were packed into polyethylene zip-up bags and stored in darkness.

Out of $600 \mathrm{~g}$ of the vegetable input, five freeze-dried vegetable snacks ( $5 \mathrm{~g}$ in average weight) were obtained. The properties of freeze-dried vegetable snacks were determined using 15 randomly selected snacks as the output of five technological cycles.

\section{Monitoring drying kinetics}

During the freeze-drying process, changes in the weight of the snacks were recorded with special software (SWL0125, Mensor, Ząbki, Poland) every $5 \mathrm{~min}$ for the first $120 \mathrm{~min}$ of the drying process and subsequently every 15 min until the end of the freeze-drying process. The samples were dried

TABLE 1. Composition of the freeze-dried vegetable snacks with sodium alginate and dried apple pomace powder $(\mathrm{g} / 100 \mathrm{~g})$.

\begin{tabular}{|c|c|c|c|c|c|c|}
\hline Ingredient & YB-SA & $\mathrm{YB} / \mathrm{C}-\mathrm{SA}$ & $\mathrm{YB} / \mathrm{P} / \mathrm{C}-\mathrm{SA}$ & YB-AP & $\mathrm{YB} / \mathrm{C}-\mathrm{AP}$ & $\mathrm{YB} / \mathrm{P} / \mathrm{C}-\mathrm{AP}$ \\
\hline Yellow bean (YB) & 50 & 35 & 35 & 100 & 70 & 70 \\
\hline Carrot (C) & - & 15 & 7.5 & - & 30 & 15 \\
\hline Potato (P) & - & - & 7.5 & - & - & 15 \\
\hline Water & & 48.4 & & & - & \\
\hline Sodium alginate (SA) & & 1.5 & & & - & \\
\hline Calcium lactate & & 0.1 & & & - & \\
\hline Apple pomace (AP) & & - & & & +2 & \\
\hline
\end{tabular}


to a constant weight and the process was carried out two times for each type of vegetable snack.

Based on the recorded weight changes and dry matter contents, the drying kinetics of the freeze-dried vegetable snacks was determined and expressed in terms of the moisture content throughout the duration of the freeze-drying process. The moisture content was calculated according to the equation formula:

$$
u=\frac{m_{\mathrm{t}}-m_{\mathrm{e}}}{m_{\mathrm{e}} \times d m_{\mathrm{e}}}
$$

where: $u$ is moisture content ( $\mathrm{g} \mathrm{H}_{2} \mathrm{O} / \mathrm{g}$ dry matter (d.m.)), $m_{\mathrm{t}}$ is product weight while being dried $(\mathrm{g}), m_{\mathrm{e}}$ is dried product residual weight $(\mathrm{g})$ and $d m_{\mathrm{e}}$ is the dry matter content of a dried product $(\mathrm{g} / 100 \mathrm{~g})$.

\section{Dry matter content determination}

Water content was determined by hot air drying of 0.5 to $1 \mathrm{~g}$ of vegetable snacks before and after freeze-drying in a convective dryer SUP $65 \mathrm{~W} / \mathrm{G}$ (WAMED, Warsaw, Poland) at $70^{\circ} \mathrm{C}$ for $24 \mathrm{~h}$, according to Association of Official Analytical Chemists (AOAC) procedure [AOAC, 2002]. After drying, the samples were chilled in a desiccator and weighed again. The water content of the samples was calculated in terms of the difference in weight before and after drying divided by the weight of the sample before drying. Measurements were taken three times for each sample.

\section{Water activity measurement}

The water activity of freeze-dried vegetable snacks was measured using HygroLab C1 meter (Rotronic AG, Bassersdorf, Switzerland) at $25 \pm 1^{\circ} \mathrm{C}$. Measurements of each sample were performed in triplicate according to the manufacturer's instructions.

\section{True density determination}

The volume of the dried solid matter was measured using a helium pycnometer (Quantachrome Instruments, Boynton Beach, FL, USA) according to the method described by Tsami et al. [1998]. The sample was placed into a large measurement cell and cleaned with helium three times before measurement. A pycnometer software (version 2.7) was used for converting the results into true density. The procedure was performed three times for each sample.

\section{Apparent density determination}

The apparent density of the freeze-dried vegetable snacks was determined using the modified method presented by Tsami et al. [1998] using chia seed displacement. The weighed cuboidal samples were put in a glass cylinder that was then filled up with chia seeds to reach a volume of $25 \mathrm{~mL}$. The measurement was performed ten times for each freeze-dried snack. The apparent density was calculated in terms of the ratio of the weight to the geometric sample volume.

\section{Analysis of textural properties}

The textural properties of the freeze-dried vegetable snacks were determined by the modified method described by Meullenet \& Gross [1999]. A compression test was conducted in a TA.HD plus texture analyser (Stable Micro Systems, Surrey, UK) using a $20 \mathrm{~mm}$ diameter platen probe, applying a test speed of $0.5 \mathrm{~mm} / \mathrm{s}$. The measurement was performed on twenty cuboid samples of the freeze-dried vegetable snacks $(1 \times 1 \times 1 \mathrm{~cm})$ until $50 \%$ deformation of their initial height was obtained. The compression force was recorded by the Texture Export software to determine compression curves and maximum force.

\section{X-Ray tomography imaging}

The microstructure of the freeze-dried vegetable snacks was analysed using the X-ray micro-CT SkyScan 1272 system (Bruker microCT, Kontich, Belgium). Cuboidal samples of the freeze-dried vegetable snacks $(1 \times 1 \times 1 \mathrm{~cm})$ were attached to the rotation stage using double-sided adhesive tape. Measurements were performed based on the following parameters: a pixel size of $13.4 \mu \mathrm{m}$, accelerating voltage of $40 \mathrm{kV}$ and $193 \mu \mathrm{A}$ of supply current. To obtain a radiographic image size of 2016 by 2016 pixels, the samples were rotated every $0.2^{\circ}$ step until the full rotation of $360^{\circ}$. The output images were loaded into the NRecon1.6.3.2 computer program (Bruker microCT) and converted into a $3 \mathrm{D}$ reconstruction of the sample. The greyscale images were binarised by using the lower intensity pixels as the background (air, pores) and higher intensity pixels as the freeze-dried snack input. The porosity and mean pore distribution were calculated based on the 3D data using CTAn v.1.10.1.0 software (Bruker microCT) [Gondek et al., 2013].

\section{Colour analysis}

The colour of freeze-dried vegetable snacks was determined using a Konica-Minolta CM-5 colorimeter (Osaka, Japan). The CIE L*a*b* system (CIE standard Illuminate D65, an angle of $0^{\circ}$, the diameter of the measurement hole equalled $8 \mathrm{~mm}$ ) and the reflectance mode were used. Before the measurement, the colorimeter was calibrated with black and white reference tiles. The lightness $\left(L^{*}\right)$, redness $\left(a^{*}\right)$ and yellowness $\left(b^{*}\right)$ were measured within 20 repetitions. To evaluate the colour changes, the total colour difference $(\Delta E)$ was calculated according to the following equation formula [Methakhup et al., 2005]:

$$
\Delta E=\sqrt{\left(\Delta L^{*}\right)^{2}+\left(\Delta a^{*}\right)^{2}+\left(\Delta b^{*}\right)^{2}}
$$

where: $\Delta L^{*}, \Delta a^{*}, \Delta b^{*}$ are the differences in lightness $\left(L^{*}\right)$, redness $\left(a^{*}\right)$ and yellowness $\left(b^{*}\right)$ between the vegetable snacks before and after freeze-drying.

\section{Extract preparation}

The extract of the freeze-dried vegetable snacks was prepared using $25 \mathrm{~mL}$ of an $80 \%(\mathrm{v} / \mathrm{v})$ aqueous ethanol solution (Avantor Performance Materials, Gliwice, Poland) and $2 \mathrm{~g}$ of the freeze-dried snack ground in an analytical mill (IKA A11 basic, IKA Werke GmbH \& Co. KG, Staufen, Germany). The mixture was warmed to $80^{\circ} \mathrm{C}$ and then filtered. The filtrate was transferred into a volumetric flask and filled with an $80 \%(v / v)$ ethanol solution up to $50 \mathrm{~mL}$. This procedure was performed three times for each sample. The extracts were used to determine the total phenolic contents (TPC) and the antioxidant capacity of the snacks. 


\section{Total phenolic content determination}

The TPC was determined according to Singleton et al. [1999] method. The volumes of $0.18 \mathrm{~mL}$ of the extract of the vegetable snacks and $0.3 \mathrm{~mL}$ of Folin-Ciocalteau's reagent (Merck, Darmstadt, Germany) were put into a glass tube filled in with $4.82 \mathrm{~mL}$ of distilled water. The tube was stirred and left in the ambient temperature for $3 \mathrm{~min}$. Next, $0.6 \mathrm{~mL}$ of saturated sodium carbonate (Avantor Performance Materials) was added, the mixture was stirred again and left in darkness for $1 \mathrm{~h}$. The absorbance of mixtures was measured using a spectrophotometer (Helios Gamma, Thermo Fisher Scientific, Waltham, MA, USA) at a $750 \mathrm{~nm}$ wavelength versus a blank sample of distilled water with Folin-Ciocalteau's reagent and without any extract. The TPC was expressed in terms of gallic acid equivalents (GAE) per $100 \mathrm{~g}$ of snack d.m. The analysis was performed twice for each extract.

\section{Antioxidant capacity determination using DPPH assay}

To determine antioxidant capacity of the freeze-dried vegetable snacks using the DPPH assay [Brand-Williams et al., 1995], $16 \mathrm{~h}$ before the analysis, 2,2-diphenyl-1-picrylhydrazyl radical $\left(\mathrm{DPPH}^{\bullet}\right)$ solution was prepared by dissolving $\mathrm{DPPH}^{*}$ (Sigma-Aldrich, Steinheim, Germany) in methanol and stored at $4^{\circ} \mathrm{C}$ in darkness. Directly before the analysis, the DPPH ${ }^{\circ}$ solution was diluted by mixing with an $80 \%(v / v)$ aqueous ethanol solution to a final solution absorbance within the range of $0.680-0.720$ at $515 \mathrm{~nm}$. Various volumes $(0.1,0.2,0.3$, $0.4 \mathrm{~mL}$ ) of the extract of snacks were put into separate glass tubes and filled with $80 \%$ ethanol up to $2 \mathrm{~mL}$. These mixtures were supplemented with $2 \mathrm{~mL}$ of a DPPH${ }^{*}$ solution. After stirring for $30 \mathrm{~min}$ in darkness at room temperature, the absorbance was measured at $515 \mathrm{~nm}$ using a Helios Gamma spectrophotometer (Thermo Fisher Scientific) versus an $80 \%$ $(v / v)$ aqueous ethanol solution as a blank sample. The assay was carried out twice for each extract. The results were expressed in terms of the $\mathrm{EC}_{50}$, proving that the extract concentration had the ability to scavenge $50 \%$ of $\mathrm{DPPH}^{\circ}$. The results were expressed in $\mathrm{mg}$ of snack d.m. per $\mathrm{mL}$ of the extract.

\section{Antioxidant capacity determination using ABTS assay}

To determine the antioxidant capacity of the freeze-dried vegetable snacks using the ABTS assay [Re et al., 1999], an ABTS radical cation solution was prepared by dissolving persulfate (Sigma-Aldrich) and ABTS (Sigma-Aldrich) in the distilled water and storing it for $16 \mathrm{~h}$ in darkness to obtain $7 \mathrm{mM}$ solutions. Before the analysis, the ABTS ${ }^{++}$solution was mixed with an $80 \%(v / v)$ aqueous ethanol solution to obtain the reagent proving the absorbance ranging from 0.680 to 0.720 at $734 \mathrm{~nm}$. Varied volumes $(0.025,0.05,0.075$, $0.1 \mathrm{~mL}$ ) of freeze-dried vegetable snack extracts were put into glass tubes, and $3 \mathrm{~mL}$ of the $\mathrm{ABTS}^{\cdot+}$ solution was added. The tubes were then stirred and kept for 6 min in darkness at the ambient temperature. The $80 \%(\mathrm{v} / \mathrm{v})$ aqueous ethanol solution served as a blank sample. The absorbance of mixtures was measured at $734 \mathrm{~nm}$ using a Helios Gamma spectrophotometer (Thermo Fisher Scientific). The assay was carried out twice for each extract. The results were expressed in terms of the $\mathrm{EC}_{50}$ (mg d.m./mL).

\section{Statistical analysis}

To identify significant differences between the values for tested snacks, the ANOVA with Tukey's post-hoc test (at $p<0.05$ ) were performed. Moreover, in order to recognise the relationship between the parameters, Pearson's correlation analysis was carried out and correlation coefficient (r) was determined. The statistical analysis was carried out using STATISTICA 13 software (TIBCO Software, Palo Alto, CA, USA).

\section{RESULTS AND DISCUSSION}

The dry matter contents of vegetable snacks before and after drying are shown in Table 2. The dry matter content of fresh vegetable pulps with dried apple pomace powder was $10.36 \mathrm{~g} / 100 \mathrm{~g}$ to $10.70 \mathrm{~g} / 100 \mathrm{~g}$. The addition of the sodium alginate as a structure-forming component caused the need for water. Therefore, the initial dry matter content was significantly lower $(6.29 \mathrm{~g} / 100 \mathrm{~g}$ to $6.76 \mathrm{~g} / 100 \mathrm{~g})$ in the output obtained using a hydrocolloid. There were no significant $(p \geq 0.05)$ differences between the dry matter content of the samples with homogenous additive components and varied vegetable ingredients. Water removal during the freeze-drying reduced the weight of the snacks with SA and AP by $94.20 \%$ and $89.11 \%$, respectively. The dried

TABLE 2. Dry matter content of vegetable snacks with sodium alginate (SA) and dried apple pomace powder (AP) before and after freeze-drying process, and water activity of the freeze-dried products.

\begin{tabular}{|c|c|c|c|}
\hline Snack & $\begin{array}{c}\text { Dry matter content } \\
\text { before drying }(\mathrm{g} / 100 \mathrm{~g})\end{array}$ & $\begin{array}{c}\text { Dry matter content } \\
\text { after drying }(\mathrm{g} / 100 \mathrm{~g})\end{array}$ & $\begin{array}{c}\text { Water } \\
\text { activity }\end{array}$ \\
\hline YB-SA & $6.29 \pm 0.21^{\mathrm{b}}$ & $97.19 \pm 0.19^{b}$ & $0.012 \pm 0.003^{\mathrm{a}}$ \\
\hline $\mathrm{YB} / \mathrm{C}-\mathrm{SA}$ & $6.39 \pm 0.16^{\mathrm{b}}$ & $97.31 \pm 0.20^{\mathrm{b}}$ & $0.013 \pm 0.002^{\mathrm{a}}$ \\
\hline $\mathrm{YB} / \mathrm{P} / \mathrm{C}-\mathrm{SA}$ & $6.76 \pm 0.13^{b}$ & $97.31 \pm 0.29^{b}$ & $0.010 \pm 0.002^{2 \mathrm{ab}}$ \\
\hline YB-AP & $10.52 \pm 0.18^{\mathrm{a}}$ & $98.35 \pm 0.02^{\mathrm{a}}$ & $0.009 \pm 0.003^{\mathrm{ab}}$ \\
\hline $\mathrm{YB} / \mathrm{C}-\mathrm{AP}$ & $10.36 \pm 0.16^{\mathrm{a}}$ & $98.27 \pm 0.11^{\mathrm{a}}$ & $0.010 \pm 0.002^{\mathrm{ab}}$ \\
\hline YB/P/C-AP & $10.70 \pm 0.29^{a}$ & $98.20 \pm 0.15^{\mathrm{a}}$ & $0.006 \pm 0.002^{b}$ \\
\hline
\end{tabular}

Results are expressed as mean \pm standard deviation. Different letters $(\mathrm{a}, \mathrm{b})$ in columns indicate significant differences at $p<0.05$. Vegetable ingredients: yellow bean $(\mathrm{YB})$, carrot $(\mathrm{C})$ and potato $(\mathrm{P})$. 


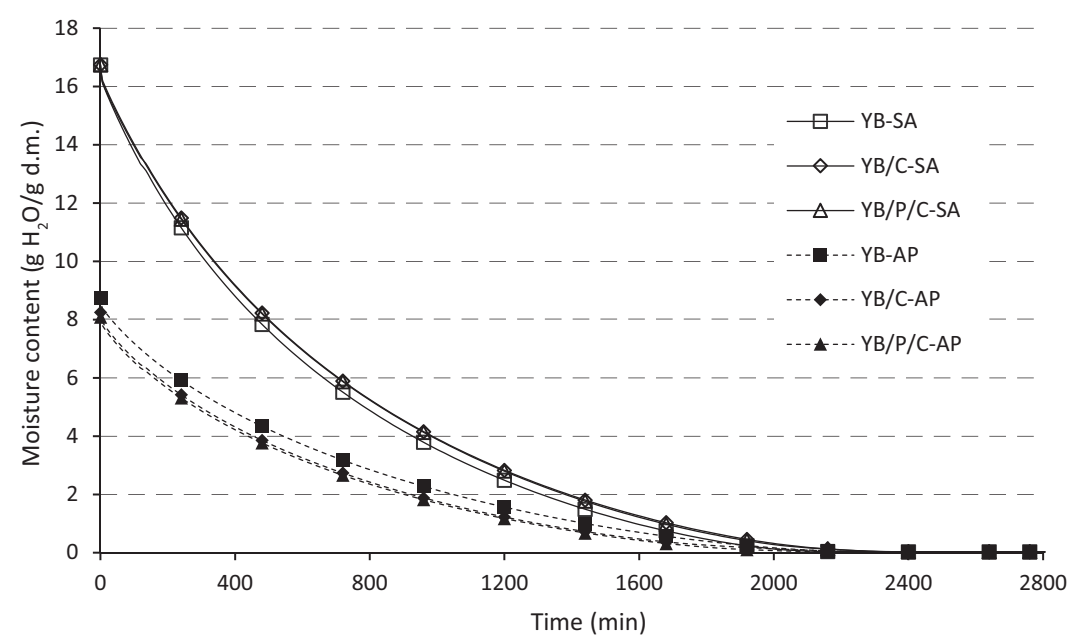

FIGURE 1. Drying kinetic curves obtained for freeze-drying of vegetable snacks with sodium alginate (SA) and dried apple pomace powder (AP) at $30^{\circ} \mathrm{C}$. Vegetable ingredients: yellow bean $(\mathrm{YB})$, carrot $(\mathrm{C})$ and potato $(\mathrm{P})$.

materials were characterised by a very high dry matter content and a corresponding low water content, which indicated very low water activity $(0.006-0.013)$. Although the type of additive significantly affected the water content of the samples, the corresponding differences were not evidently reflected by water activity. Similar results of the low water activity and high dry matter content of freeze-dried vegetable snacks with hydrocolloids were obtained by Ciurzyńska et al. [2020]. Low water content and activity are factors that restrain chemical and biochemical reactions in food products. They also inhibit the development of microorganisms, thus affecting the safety and stability of products and prolonging their shelf life [Rahman \& Labuza, 2020].

Freeze-drying kinetic curves are presented in Figure 1. They show changes in the moisture content in the dried output in terms of the dehydration process duration. The type of used additive determined the drying course. The initial moisture content of the samples with an addition of SA was about two times higher than in the case of the samples with AP. Such a phenomenon was caused by the addition of water to snacks with SA, as mentioned above. The equilibrium moisture content achieved by the end of the freeze-drying process was $0.028 \mathrm{~g} \mathrm{H}_{2} \mathrm{O} / \mathrm{g}$ d.m. for the input supplemented with $\mathrm{SA}$ and $0.018 \mathrm{~g} \mathrm{H}_{2} \mathrm{O} / \mathrm{g} \mathrm{d}$.m. for the samples with the AP addition. The type of the additive also influenced the duration of drying, which was about 2,800 min for each snack containing the SA and 2,760 min for the AP samples. The drying time of vegetable snacks was determined by the parameters of the freezedrying process (temperature and pressure) selected in the preliminary tests. The preliminary experiments were conducted for about two days at a shelf temperature of $30^{\circ} \mathrm{C}$ and at a pressure of $63 \mathrm{~Pa}$, which allowed obtaining a product with an appropriate structure and texture that accounted for the features that matter to a possible snack consumer. At the same time, the process duration was determined by measuring the temperature in the thermal centre of the freeze-dried vegetable snacks until the pre-set temperature of the shelf in the device was reached to be consistent with the procedure relevant to the freeze-drying porous amorphous products [Ciurzyńska \&
Lenart, 2011]. The course of the drying curves indicates that, in this study, the freeze-drying process depended on the moisture content of the experimental input. A lower rate of water removal at the same temperature and pressure resulted from a lower moisture content. The freeze-drying process course is affected by the sample thickness, while the size of ice crystals depends on the moisture content in the fresh sample and the composition of the matrix, as well as the process conditions such as temperature and pressure [Oyinloye \& Yoon, 2020]. Due to the processing parameters and the very low moisture content, freeze-dried products are usually in an amorphous state, which ensures their textural and structural properties. However, since they are also very prone to adsorb water, and hydrocolloids are also characterised by a high ability to retain water, the drying process needs to be carried out until the moisture content is low in order to prevent glass transition and structure collapse [Cassanelli et al., 2018; Silva-Espinoza et al., 2020].

The true density of the freeze-dried vegetable snacks in terms of the density of the solid material is shown in Table 3. The snacks obtained by adding the apple pomace powder were characterised by $7 \%$ higher true density than the input supplemented with sodium alginate. The true density of the products was also dependent on vegetable ingredients. Irrespective of any carrier agent, the lowest values of the true density were obtained for the snacks containing only blanched yellow bean (YB-SA and YB-AP), whereas cooked potato puree caused an increase in the true density, and the highest values were noted for the $\mathrm{YB} / \mathrm{P} / \mathrm{C}-\mathrm{SA}$ and $\mathrm{YB} / \mathrm{P} / \mathrm{C}-\mathrm{AP}$. Oikonomopoulou et al. [2011] demonstrated that the true density of freeze-dried agricultural products and mushrooms significantly differed from one another and depended on the type of pre-treatment used (e.g. boiling duration). Such results were probably caused by differences in the molecular weight of the skeletal compounds of the snacks and the presence of small, closed pores. However, according to Marques et al. [2006] using helium allows penetrating all small and closed pores during measurement. Koua et al. [2019] also noted the relationship between the moisture content and the true density of the dried input, 
TABLE 3. True and apparent density, porosity and hardness of freeze-dried vegetable snacks with sodium alginate (SA) and dried apple pomace powder (AP).

\begin{tabular}{lccccc}
\hline Snack & True density $\left(\mathrm{g} / \mathrm{cm}^{3}\right)$ & Apparent density $\left(\mathrm{g} / \mathrm{cm}^{3}\right)$ & Porosity $(\%)$ & Hardness $(\mathrm{N})$ \\
\hline YB-SA & $1.460 \pm 0.002^{\mathrm{f}}$ & $0.073 \pm 0.003^{\mathrm{c}}$ & $69.46 \pm 2.51^{\mathrm{ab}}$ & $20.29 \pm 2.93^{\mathrm{b}}$ \\
YB/C-SA & $1.469 \pm 0.000^{\mathrm{e}}$ & $0.065 \pm 0.004^{\mathrm{d}}$ & $73.90 \pm 3.73^{\mathrm{a}}$ & $18.94 \pm 2.79^{\mathrm{cb}}$ \\
YB/P/C-SA & $1.478 \pm 0.001^{\mathrm{d}}$ & $0.075 \pm 0.004^{\mathrm{c}}$ & $65.65 \pm 1.10^{\mathrm{abc}}$ & $27.36 \pm 1.64^{\mathrm{a}}$ \\
YB-AP & $1.578 \pm 0.001^{\mathrm{c}}$ & $0.135 \pm 0.009^{\mathrm{b}}$ & $59.39 \pm 2.34^{\mathrm{c}}$ & $12.71 \pm 1.95^{\mathrm{e}}$ \\
YB/C-AP & $1.583 \pm 0.001^{\mathrm{b}}$ & $0.130 \pm 0.005^{\mathrm{b}}$ & $64.11 \pm 0.32^{\mathrm{bc}}$ & $15.29 \pm 2.52^{\mathrm{d}}$ \\
YB/P/C-AP & $1.596 \pm 0.001^{\mathrm{a}}$ & $0.143 \pm 0.006^{\mathrm{a}}$ & $61.43 \pm 1.68^{\mathrm{bc}}$ & $16.83 \pm 2.56^{\mathrm{cd}}$ \\
\hline
\end{tabular}

Results are expressed as mean \pm standard deviation. Different letters $\left({ }^{(a, b, c, d, d, f}\right)$ in columns indicate significant differences at $p<0.05$. Vegetable ingredients: yellow bean $(\mathrm{YB})$, carrot $(\mathrm{C})$ and potato $(\mathrm{P})$.

but in the current study, the samples containing less water were characterised by a higher true density and in the aforementioned study it was reverse.

The capacity of the hydrocolloids to create a porous structure also influenced the apparent density of the freeze-dried snacks (Table 3), which was $46 \%$ to $50 \%$ lower for the samples supplemented with sodium alginate (SA) than it was for the AP variants. The apparent density was strongly correlated with the true density of the input $(r=0.99)$. Since using a hydrocolloid compound allowed for the preservation of the structure during freeze-drying, a smaller weight of the substance occupied a similar volume as the AP samples. Hydrocolloids are prone to creating a porous structure by using mixing and aerating devices such as blenders [Ciurzyńska et al., 2017], and in such cases, replacement of the sodium alginate with apple pomace powder led to the formation of a structure with a smaller amount of closed pores and caused a higher content of the solid mass inside the sample. The differences in the internal structure of the snacks are presented in Figure 2. According to the displayed cross-section scans and 3D visualisations, the skeletal elements were much more condensed in the case of the snacks with the addition of AP than in the case of the products with SA. As shown in Figure 3, for the snacks supplemented with SA, the more frequent appearance of pores with a mean diameter larger than $0.16 \mathrm{~mm}$ was observed, while in the AP snacks, a larger number of smaller pores with a mean diameter lower than $0.10 \mathrm{~mm}$ was noted. The hydrophilic nature of sodium alginate reduces the mobility of water [Rhim, 2004; Borchard et al., 2005], which induces the formation of large ice crystals and, consequently, a larger size of pores compared to the addition of dried apple pomace powder. The type of carrier agent also affected the total porosity of the freeze-dried snacks (Table 3). Porosity ranged from $59.39 \%$ to $73.90 \%$ and lower results were received for snacks with the addition of dried apple pomace powder. There was a strong negative correlation between the porosity and density results $\left(\mathrm{r}_{\text {true density }}=-0.83, \mathrm{r}_{\text {apparent density }}=-0.87\right)$. During freeze-drying, since pores are created where ice crystals are removed [Voda et al., 2012], the presented outcomes could also be caused by the amount of water removed from the sample. The water content was higher in the products supplemented with sodium alginate. Differences in the apparent density, porosity and pore distribution arise from the type of additive and technological process that was consistent with the specific nature of the carrier agent used. Mixing ingredients of the snacks with a whisk initiated aeration of the hydrocolloid, which resulted in a very porous structure. For a dried apple pomace powder addition, since aeration was absent and the cellular composition of ingredients was destroyed by grinding, the pores were smaller and porosity was lower in these snacks. The porosity and apparent density of freeze-dried agricultural products depended on the duration of thermal pre-treatment and drying conditions. Since the pressure in a drying chamber influenced those features, higher porosity

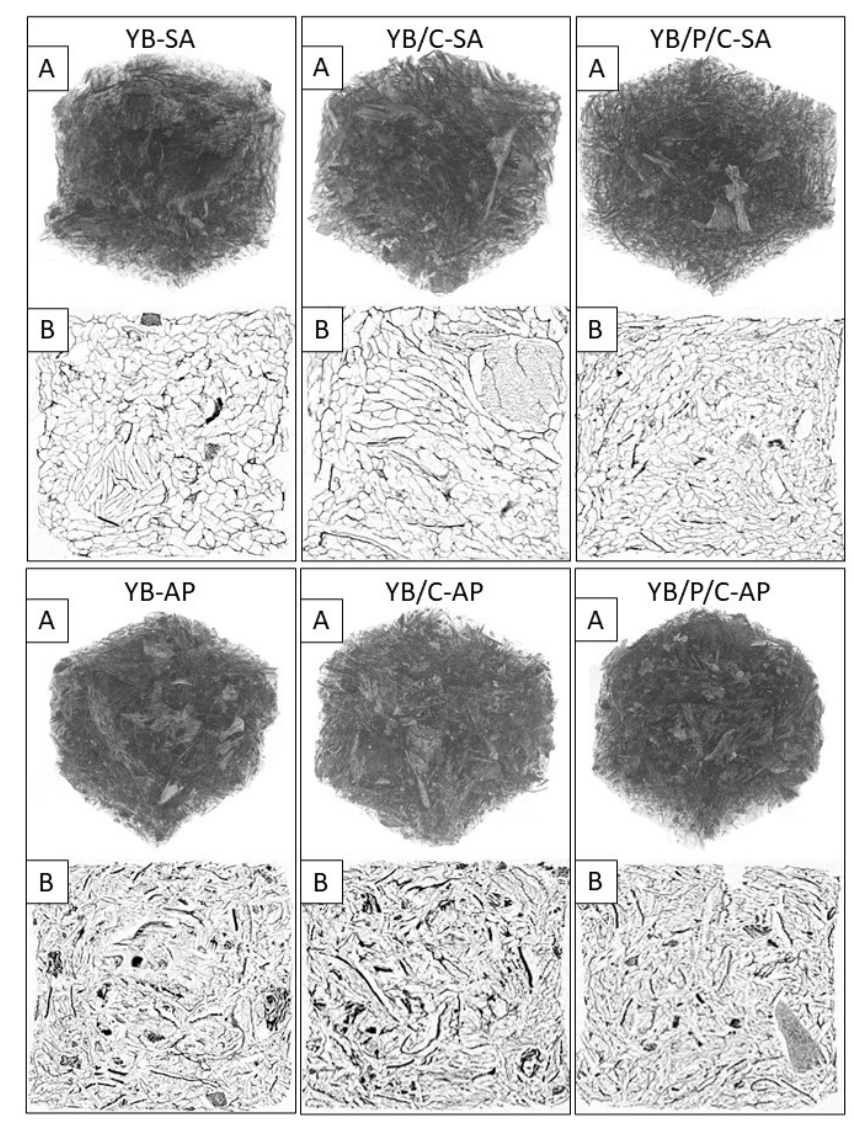

FIGURE 2. 3D images (A) and the cross-section (B) of freeze-dried vegetable snacks with sodium alginate (SA) and dried apple pomace powder (AP). Vegetable ingredients: yellow bean (YB), carrot $(\mathrm{C})$ and potato $(\mathrm{P})$. 


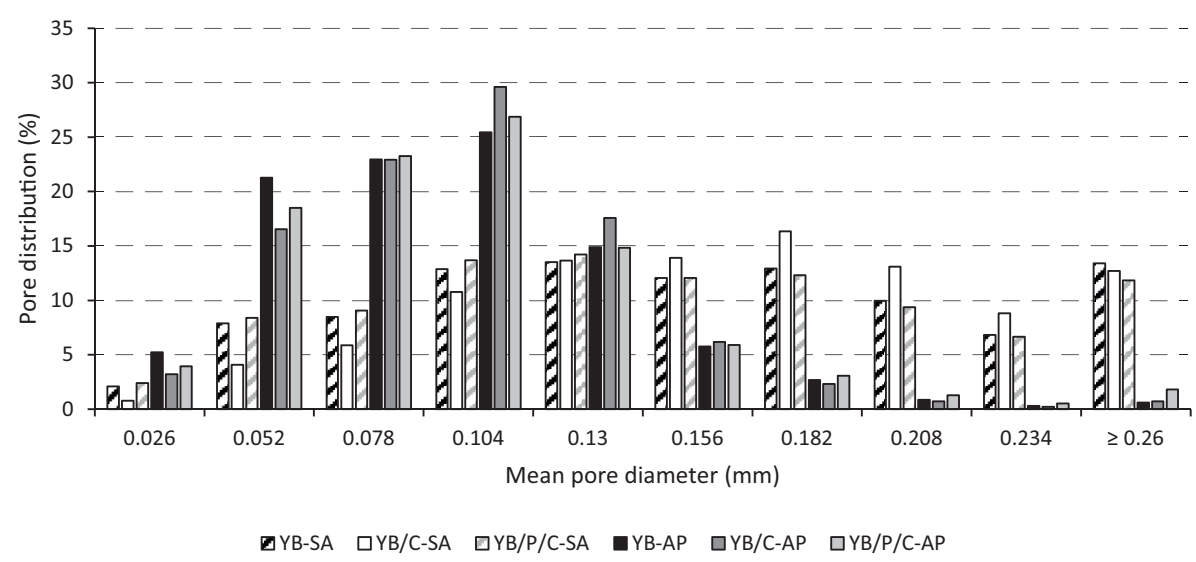

FIGURE 3. Percentage distribution of pore sizes in freeze-dried vegetable snacks with sodium alginate (SA) and dried apple pomace powder (AP). Vegetable ingredients: yellow bean $(\mathrm{YB})$, carrot $(\mathrm{C})$ and potato $(\mathrm{P})$.

and a lower apparent density were caused by the low pressure in the drying chamber [Oikonomopoulou et al., 2011].

The type of additive also affected the textural properties of the freeze-dried vegetable snacks, which happens to be almost as important as sensory properties for both consumers and manufacturers. In general, products obtained after adding dried apple pomace powder were characterised by lower hardness (12.71-16.83 N) than the snacks supplemented with sodium alginate (18.94-27.36 N), as expressed in terms of the maximum force recorded during a compression test (Table 3). However, there were similarities between $\mathrm{YB} / \mathrm{P} / \mathrm{C}-\mathrm{AP}$ and $\mathrm{YB} / \mathrm{C}-\mathrm{SA}$ variants. A higher hardness was correlated with a more stable internal structure of the tested sample. For both the $\mathrm{AP}$ and $\mathrm{SA}$ additives, the $\mathrm{YB} / \mathrm{P} / \mathrm{C}$ snacks were characterised by the highest hardness value, which was induced by the structure and texture-forming properties of the starch contained in the cooked potato puree [Pieniazek \& Messina, 2017]. The type of the carrier agent determined not only the hardness of the freeze-dried snacks, but also the course of the compression curves presented in Figure 4. The SA sample curves were full of periodic drops of compression force, while for snacks with the AP addition they were much smoother, and some drops appeared only on the $\mathrm{YB} / \mathrm{P} / \mathrm{C}-\mathrm{AP}$ curve. The occurrence of these drops indicated the cracking of the internal structure of the sample as a result of the applied force. For snacks with added AP, the course of the curves was softer because they were compressed without breaking

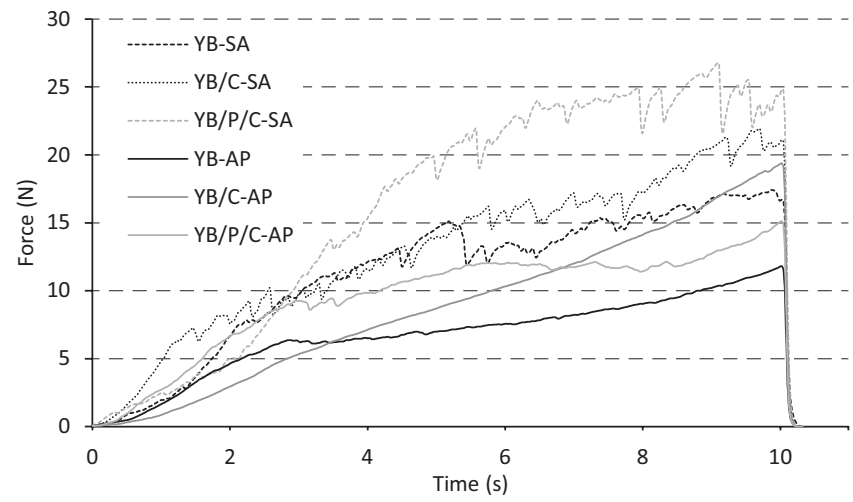

FIGURE 4. Example compression curves of freeze-dried vegetable snacks with sodium alginate (SA) and dried apple pomace powder (AP). Vegetable ingredients: yellow bean (YB), carrot $(\mathrm{C})$ and potato $(\mathrm{P})$.

and cracking, except for the $\mathrm{YB} / \mathrm{P} / \mathrm{C}-\mathrm{AP}$ variant, which was harder. Internal cracks were characteristic of fragile and dry input, especially in samples obtained with the freeze-drying method [Rowicka et al., 2002].

The colour parameters of the freeze-dried vegetable snacks are presented in Table 4 . The $L^{*}$ values of snacks before drying ranged from 53.69 to 57.39 . There were no significant $(p \geq 0.05)$ differences between the YB samples with the addition of sodium alginate and apple pomace powder, but for other recipes $L^{*}$ was lower for the AP samples than for

TABLE 4. Colour parameters of freeze-dried vegetable snacks with sodium alginate (SA) and dried apple pomace powder (AP).

\begin{tabular}{l|c|c|c|c|c|c|c}
\hline Snack & $L^{*}$ before drying & $a^{*}$ before drying & $b^{*}$ before drying & $L^{*}$ after drying & $a^{*}$ after drying & $b^{*}$ after drying & $\Delta E$ \\
\hline YB-SA & $57.35 \pm 0.20^{\mathrm{a}}$ & $-5.35 \pm 0.11^{\mathrm{e}}$ & $31.51 \pm 0.20^{\mathrm{e}}$ & $76.45 \pm 1.43^{\mathrm{a}}$ & $-10.62 \pm 0.41^{\mathrm{e}}$ & $34.56 \pm 0.91^{\mathrm{a}}$ & $17.09 \pm 1.02^{\mathrm{c}}$ \\
YB/C-SA & $54.33 \pm 0.24^{\mathrm{d}}$ & $8.93 \pm 0.66^{\mathrm{b}}$ & $35.16 \pm 0.19^{\mathrm{b}}$ & $71.49 \pm 1.69^{\mathrm{bc}}$ & $4.76 \pm 2.17^{\mathrm{b}}$ & $25.29 \pm 2.13^{\mathrm{c}}$ & $18.27 \pm 2.94^{\mathrm{bc}}$ \\
YB/P/C-SA & $57.13 \pm 0.14^{\mathrm{b}}$ & $1.75 \pm 0.15^{\mathrm{d}}$ & $31.91 \pm 0.16^{\mathrm{d}}$ & $74.11 \pm 1.1^{\mathrm{ab}}$ & $-2.94 \pm 0.47^{\mathrm{d}}$ & $23.69 \pm 2.92^{\mathrm{c}}$ & $19.42 \pm 3.45^{\mathrm{ab}}$ \\
YB-AP & $57.39 \pm 0.04^{\mathrm{a}}$ & $1.48 \pm 0.04^{\mathrm{d}}$ & $31.94 \pm 0.07^{\mathrm{d}}$ & $75.32 \pm 2.77^{\mathrm{ab}}$ & $-3.14 \pm 0.48^{\mathrm{d}}$ & $30.67 \pm 1.33^{\mathrm{b}}$ & $19.71 \pm 1.45^{\mathrm{ab}}$ \\
YB/C-AP & $53.69 \pm 0.05^{\mathrm{d}}$ & $13.32 \pm 0.22^{\mathrm{a}}$ & $36.35 \pm 0.11^{\mathrm{a}}$ & $69.12 \pm 2.87^{\mathrm{c}}$ & $6.62 \pm 1.91^{\mathrm{a}}$ & $34.23 \pm 2.76^{\mathrm{a}}$ & $19.38 \pm 1.98^{\mathrm{ab}}$ \\
YB/P/C-AP & $54.49 \pm 0.07^{\mathrm{c}}$ & $7.42 \pm 0.19^{\mathrm{c}}$ & $32.38 \pm 0.14^{\mathrm{c}}$ & $68.54 \pm 1.41^{\mathrm{c}}$ & $0.89 \pm 0.95^{\mathrm{c}}$ & $32.08 \pm 1.53^{\mathrm{b}}$ & $20.75 \pm 1.14^{\mathrm{a}}$ \\
\hline
\end{tabular}

Results are expressed as means \pm standard deviation. Different letters (a,b,c,d,e) in columns indicate significant differences at $p<0.05$. Vegetable ingredients: yellow bean $(\mathrm{YB})$, carrot $(\mathrm{C})$ and potato $(\mathrm{P})$. Colour parameters: lightness $\left(L^{*}\right)$, redness $\left(a^{*}\right)$, yellowness $\left(b^{*}\right)$ and total colour difference $(\Delta E)$. 
the SA samples, which means that the snacks with apple pomace powder were darker. After freeze-drying, the $L^{*}$ parameter of each sample increased. The aforementioned trends were also relevant to the dried products, and the snacks with SA were characterised by higher lightness than the AP samples.

Chroma parameter $a^{*}$, which accounts for greenness and redness, was the lowest for the YB snacks and was the highest for the $\mathrm{YB} / \mathrm{C}$, regardless of the carrier agent used (Table 4). This trend occurred both before drying and for freeze-dried snacks and was related to the quantity of carrot contained in vegetable mixes, which caused the insertion of orange colorants such as carotenoids. The type of additive caused $a^{*}$ parameter of each vegetable variant to be significantly higher for the input with AP than for the samples supplemented with AS. If $a^{*}$ parameter went up, those samples were redder, which was caused by the colour of dried pomace powder that could contain enzymatic and thermal browning products [Krokida et al., 1998], which resulted from pressing the juice and drying the pomace.

The values of chroma parameter $b^{*}$ were positive for every tested sample (Table 4). Such results meant that each snack, regardless of the vegetable composition or the type of additive used, was yellow, and no blue shades were noted. Fresh vegetable pulps with an addition of SA were characterised by significantly $(p<0.05)$ lower yellowness, but after freeze-drying, $b^{*}$ parameters of the SA products increased while $b^{*}$ of snacks with AP decreased. The AP freeze-dried vegetable snacks were also characterised by higher yellowness than the SA products.

The influence of an apple pomace addition on the colour parameters in various food products was compiled by Antonic et al. [2020] and, in most cases, the products were darker and characterised by higher $a^{*}$ and $b^{*}$ parameters. Although the colour changes were usually regarded as a quality-decreasing factor, an increase in nutritive value and sensory features was also observed.

The total colour change that occurred during the freeze-drying process, expressed as $\Delta E$, ranged from 17.09 to 20.75 (Table 4), as noted for the YB-SA and YB/P/C-AP, respectively. Neither the addition of the sodium alginate nor the dried apple pomace powder caused a significantly higher

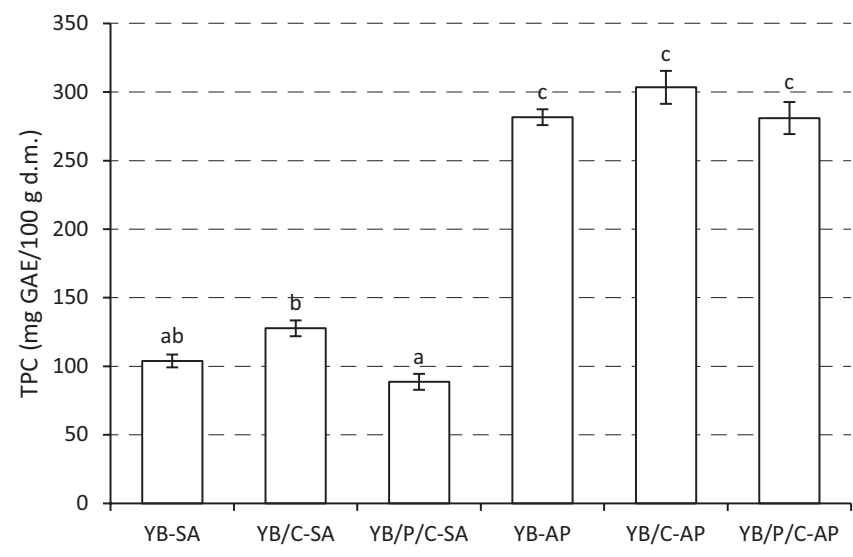

FIGURE 5. Total phenolic content (TPC) of freeze-dried vegetable snacks with sodium alginate (SA) and dried apple pomace powder (AP). Vegetable ingredients: yellow bean (YB), carrot $(\mathrm{C})$ and potato $(\mathrm{P})$ The different letters above bars indicate that the values differ significantly $(p<0.05)$. or lower change in the colour of every vegetable mix. The total colour change involved the increase in lightness and greenness, decrease in redness, as well as changes in yellowness, which appeared to have been caused by the freeze-drying process. Freeze-drying is known as the dehydration method that causes the lowest colour change compared to other drying methods [Krokida et al., 2001; Zalewska et al., 2016].

The total phenolic content (TPC) of freeze-dried vegetable snacks is presented in Figure 5. The products obtained using dried apple pomace powder, i.e. the YB-AP, YB/C-AP and $\mathrm{YB} / \mathrm{P} / \mathrm{C}-\mathrm{AP}$, contained 281.6, 303.4 and $281.0 \mathrm{mg}$ GAE/100 g d.m., while the snacks supplemented with sodium alginate contained 103.9, 127.7 and $88.7 \mathrm{mg} \mathrm{GAE} / 100 \mathrm{~g}$ d.m., respectively. According to Suárez et al. [2010] and Tarko et al. [2012], apple pomace is a rich source of phenolic compounds and may be used as an enriching additive in food products. As expected, using AP increased total phenolic contents, but it was surprising that the increases would be so much higher $(63 \%, 58 \%$ and $68 \%$ for $\mathrm{YB}, \mathrm{YB} / \mathrm{C}$ and $\mathrm{YB} / \mathrm{P} / \mathrm{C}$ variants, respectively).

The antioxidant capacity of snacks determined using DPPH and ABTS assays is shown in Figure 6, as $\mathrm{EC}_{50}$ values, which express the capacity of the snack dry matter to scavenge $50 \%$ of the $\mathrm{DPPH}^{\bullet}$ and $\mathrm{ABTS}^{\cdot+}$, respectively. To this end, the lower value indicates a higher antioxidant activity. The DPPH ${ }^{\cdot}$ scavenging capacity of $\mathrm{YB}, \mathrm{YB} / \mathrm{C}$ and $\mathrm{YB} / \mathrm{P} / \mathrm{C}$ snacks supplemented with SA was equivalent to $10.44,14.51$, $16.52 \mathrm{mg}$ d.m./mL, and for the sample supplemented with AP it was 5.03, 5.70, $6.90 \mathrm{mg} \mathrm{d.m./mL}$. The presented data shows that in comparison to sodium alginate samples, the snacks with apple pomace powder had higher antioxidant capacity by $52 \%, 61 \%$ and $58 \%$, respectively. The results obtained with the ABTS assay were 2.85, 2.04, 2.42 and 1.90, 1.92, $1.97 \mathrm{mg} \mathrm{d} . \mathrm{m} . / \mathrm{mL}$, according to the aforementioned sequence. In the cases of the $\mathrm{YB}$ and $\mathrm{YB} / \mathrm{P} / \mathrm{C}$ variants, the antioxidant capacity was higher by $33 \%$ and $19 \%$ for the AP samples, but the $\mathrm{EC}_{50}$ values of $\mathrm{YB} / \mathrm{C}$ snacks were similar $(p \geq 0.05)$, irrespective of the type of carrier agent used. The antioxidant capacity was correlated with the total phenolic content $\left(r_{\mathrm{ABTS}}=-0.76\right.$ and $\left.\mathrm{r}_{\mathrm{DPPH}}=-0.91\right)$, which means that the more

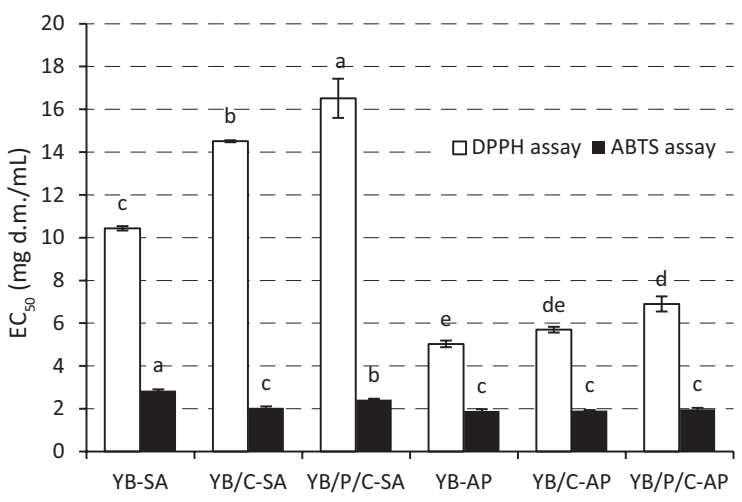

FIGURE 6. Antioxidant capacity of freeze-dried vegetable snacks with sodium alginate (SA) and dried apple pomace powder (AP) determined as $\mathrm{EC}_{50}$ using DPPH and ABTS assays. Vegetable ingredients: yellow bean $(\mathrm{YB})$, carrot $(\mathrm{C})$ and potato $(\mathrm{P})$. The different letters above bars indicate that the values differ significantly $(p<0.05)$ : a-e for results of DPPH assay; a-c for results of ABTS assay. 
phenolic compounds are contained in the input, the more radicals it is possible to scavenge. Phenolic compounds are characterised by strong antioxidant activity and, as it has been reported in the literature, during apple juice production, about $90 \%$ of them were left in the apple pomace [Wichrowska \& Żary-Sikorska 2015]. Freeze-drying is the best method in terms of retention of bioactive compounds such as phenolics, vitamins and colorants in plant products [Bhatta et al., 2020], so it is a desirable method for the production of functional food products. Nevertheless, due to the porous structure of the freeze-dried input, air with oxygen has full access to penetrate it. For this reason, since all bioactive compounds are in danger of degradation and the oxidative stability of such products is lower, appropriate packaging is necessary [Duan et al., 2016].

\section{CONCLUSIONS}

In summary, based on the presented results, using dried apple pomace powder and sodium alginate as a carrier agent to produce freeze-dried vegetable snacks produced stable products characterised by repeatable quality. The snacks supplemented with dried apple pomace powder featured higher dry matter content and density, but the sodium alginate-derived products were harder. Dried apple pomace powder improved the health-promoting properties of the snacks, such as the total phenolic content and antioxidant activity. The type of additive also affected textural properties and the internal structure of the products.

Although it is incorrect to state that food waste (particularly apple pomace) is a perfect substitute for a hydrocolloid carrier agent in the case of freeze-dried products, it is worth conducting further research on its nutritive value, sensory and storage properties and to replace only a part of the hydrocolloid with dried pomace powder to improve quality of the product and sustain its texture. Moreover, due to the high content of active ingredients, the addition of fruit pomace may increase the health attractiveness of snack products. At the same time, from an economic point of view, the addition of apple pomace may reduce the cost of producing a unit of the finished product and lower its price on store shelves.

\section{RESEARCH FUNDING}

This work was funded by the National Centre for Research and Development, as part of the III BIOSTRATEG. "The development of an innovative carbon footprint calculation method for the basic basket of food products" - task in the project "Development of healthy food production technologies taking into consideration nutritious food waste management and carbon footprint calculation methodology" BIOSTRATEG3/343817/17/NCBR/2018.

\section{CONFLICT OF INTERESTS}

Authors declare no conflict of interests.

\section{ORCID IDs}

A. Ciurzyńska https://orcid.org/0000-0001-7263-0851 M. Janowicz https://orcid.org/0000-0002-3790-3479 M. Karwacka https://orcid.org/0000-0002-5511-3251 K. Rybak https://orcid.org/0000-0003-3595-0818

\section{REFERENCES}

1. Antonic, B., Jancikova, S., Dordevic, D., Tremlova, B. (2020). Apple pomace as food fortification ingredient: A systematic review and meta-analysis. Journal of Food Science, 85(10), 2977-2985.

https://doi.org/10.1111/1750-3841.15449

2. AOAC International. Official Methods of Analysis of AOAC International, 17th ed.; AOAC International: Rockville, MD, USA, 2002.

3. Bhatta, S., Stevanovic Janezic, T., Ratti, C. (2020). Freeze-drying of plant-based foods. Foods, 9(1), art. no. 87. https://doi.org/10.3390/foods9010087

4. Borchard, W., Kenning, A., Kapp, A., Mayer, C. (2005). Phase diagram of the system sodium alginate/water: A model for biofilms. International Journal of Biological Macromolecules, 35(5), 247-256.

https://doi.org/10.1016/j.ijbiomac.2005.02.006

5. Brand-Williams, W., Cuvelier, M.E., Berset, C. (1995). Use of a free radical method to evaluate antioxidant activity. $L W T-$ Food Science and Technology, 28(1), 25-30.

https://doi.org/10.1016/s0023-6438(95)80008-5

6. Cassanelli, M., Norton, I., Mills, T. (2018). Role of gellan gum microstructure in freeze drying and rehydration mechanisms. Food Hydrocolloids, 75, 51-61.

https://doi.org/10.1016/j.foodhyd.2017.09.013

7. Ciurzyńska, A., Cieśluk, P., Barwińska, M., Marczak, W., Ordyniak, A., Lenart, A., Janowicz, M. (2019a). Eating habits and sustainable food production in the development of innovative "healthy" snacks. Sustainability, 11(10), art. no. 2800.

https://doi.org/10.3390/su11102800

8. Ciurzyńska, A., Jasiorowska, A., Ostrowska-Ligęza, E., Lenart, A. (2019b). The influence of the structure on the sorption properties and phase transition temperatures of freeze-dried gels. Journal of Food Engineering, 252, 18-27.

https://doi.org/10.1016/j.jfoodeng.2019.02.008

9. Ciurzyńska, A., Marczak, W., Lenart, A., Janowicz, M. (2020). Production of innovative freeze-dried vegetable snack with hydrocolloids in terms of technological process and carbon footprint calculation. Food Hydrocolloids, 108, art. no. 105993.

https://doi.org/10.1016/j.foodhyd.2020.105993

10. Ciurzyńska, A., Mieszkowska, A., Olsiński, I., Lenart, A. (2017). The effect of composition and aeration on selected physical and sensory properties of freeze-dried hydrocolloid gels. Food Hydrocolloids, 67, 94-103.

https://doi.org/10.1016/j.foodhyd.2016.12.042

11. Ciurzyńska, A., Lenart, A. (2011). Freeze-drying-application in food processing and biotechnology - a review. Polish Journal of Food and Nutrition Sciences, 61 (3), 165-171. https://doi.org/10.2478/v10222-011-0017-5 
12. Duan, X., Yang, X., Ren, G., Pang, Y., Liu, L., Liu, Y. (2016) Technical aspects in freeze-drying of foods. Drying Technology, 34(11), 1271-1285. https://doi.org/10.1080/07373937.2015.1099545

13. Gondek, E., Jakubczyk, E., Herremans, E., Verlinden, B., Hertog, M., Vandendriessche, T., Verboven, P., Antoniuk, A., Bongaers, E., Estrade, P., Nicolaï, B.M. (2013). Acoustic, mechanical and microstructural properties of extruded crisp bread. Journal of Cereal Science, 58(1), 132-139. https://doi.org/10.1016/j.jcs.2013.03.010

14. Karwacka, M., Ciurzyńska, A., Lenart, A., Janowicz, M. (2020). Sustainable development in the agri-food sector in terms of the carbon footprint: A Review. Sustainability, 12(16), art. no. 6463 .

\section{https://doi.org/10.3390/su12166463}

15. Koua, B.K., Koffi, P.M.E., Gbaha, P. (2019). Evolution of shrinkage, true density, porosity, heat and mass transfer coefficients during indirect solar drying of cocoa beans. Journal of the Saudi Society of Agricultural Sciences, 18(1), 72-82.

https://doi.org/10.1016/j.jssas.2017.01.002

16. Krokida, M.K., Maroulis, Z.B., Saravacos, G.D. (2001). The effect of the method of drying on the colour of dehydrated products. International Journal of Food Science \& Technology, 36(1), 53-59.

https://doi.org/10.1046/j.1365-2621.2001.00426.x

17. Krokida, M.K., Tsami, E., Maroulis, Z.B. (1998). Kinetics of color changes during drying of some fruits and vegetables. Drying Technology, 16(3-5), 667-685.

https://doi.org/10.1080/07373939808917429

18. Kruczek, M., Drygaś, B., Habryka, C. (2016). Pomace in fruit industry and their contemporary potential application. World Scientific News, 48, 259-265.

19. Kuo, C.C., Qin, H., Cheng, Y., Jiang, X., Shi, X. (2021). An integrated manufacturing strategy to fabricate delivery system using gelatin/alginate hybrid hydrogels: 3D printing and freeze-drying. Food Hydrocolloids, 111, art. no. 106262. https://doi.org/10.1016/j.foodhyd.2020.106262

20. Liew, S.Q., Teoh, W.H., Yusoff, R., Ngoh, G.C. (2019). Comparisons of process intensifying methods in the extraction of pectin from pomelo peel. Chemical Engineering and Processing - Process Intensification, 143, art. no. 107586.

https://doi.org/10.1016/j.cep.2019.107586

21. Marques, L.G., Silveira, A.M., Freire, J.T. (2006). Freeze-drying characteristics of tropical fruits. Drying Technology, 24(4), 457-463. https://doi.org/10.1080/07373930600611919

22. Masiarz, E., Kowalska, H., Bednarska, M. (2019). The application of plant pomace as a source of dietary fiber and other bio-ingredients in the creation of pro-healthy, sensory and technological properties of baking products®. Postępy Techniki Przetwórstwa Spożywczego, 1, 103-107.

23. Methakhup, S., Chiewchan, N., Devahastin, S. (2005). Effects of drying methods and conditions on drying kinetics and quality of Indian gooseberry flake. LWT - Food Science and Technology, 38(6), 579-587. https://doi.org/10.1016/j.Iwt.2004.08.012

24. Meullenet, J.F., Gross, J. (1999). Instrumental single and double compression tests to predict sensory texture characteristics of foods. Journal of Texture Studies, 30(2), 167-180. https://doi.org/10.1111/j.1745-4603.1999.tb00209.x
25. Nowak, D., Jakubczyk, E. (2020). The freeze-drying of foods The characteristic of the process course and the effect of its parameters on the physical properties of food materials. Foods, 9(10), art. no. 1488 .

https://doi.org/10.3390/foods9101488

26. Oikonomopoulou, V.P., Krokida, M.K., Karathanos, V.T. (2011). The influence of freeze drying conditions on microstructural changes of food products. Procedia Food Science, 1, 647-654. https://doi.org/10.1016/j.profoo.2011.09.097

27. Oyinloye, T.M., Yoon, W.B. (2020). Effect of freeze-drying on quality and grinding process of food produce: A review. Processes, 8(3), art. no. 354 .

https://doi.org/10.3390/pr8030354

28. Pieniazek, F., Messina, V. (2017). Texture and color analysis of freeze-dried potato (cv. Spunta) using instrumental and image analysis techniques. International Journal of Food Properties, 20(6), 1422-1431.

https://doi.org/10.1080/10942912.2016.1211143

29. Rahman, M.S., Labuza, T.P. (2020). Water activity and food preservation. In M.S. Rahman (Ed.) Handbook of Food Preservation. $3^{\text {rd }}$ edition, CRC Press, Boca Raton, pp. 487-506.

https://doi.org/10.1201/9780429091483

30. Re, R., Pellegrini, N., Proteggente, A., Pannala, A., Yang, M., Rice-Evans, C. (1999). Antioxidant activity applying an improved ABTS radical cation decolorization assay. Free Radical Biology and Medicine, 26(9-10), 1231-1237.

https://doi.org/10.1016/S0891-5849(98)00315-3

31. Rhim, J.W. (2004). Physical and mechanical properties of water resistant sodium alginate films. LWT - Food Science and Technology, 37(3), 323-330.

https://doi.org/10.1016/j.lwt.2003.09.008

32. Rowicka, R., Nowak, D., Lewicki, P.P. (2002). Effect of water activity on mechanical properties of freeze-dried apple cubes. Żywność. Nauka. Technologia. Jakość, 1(30), 66-78 (in Polish; English abstract).

33. Silva-Espinoza, M.A., del Mar Camacho, M., Martínez-Navarrete, N. (2020). Use of different biopolymers as carriers for purposes of obtaining a freeze-dried orange snack. $L W T$ - Food Science and Technology, 127, art. no. 109415.

https://doi.org/10.1016/j.lwt.2020.109415

34. Silva-Espinoza, M.A., Salvador, A., Camacho, M.D.M., Martínez-Navarrete, N. (2021). Impact of freeze-drying conditions on the sensory perception of a freeze-dried orange snack. Journal of the Science of Food and Agriculture, 101 (11), 4585-4590. https://doi.org/10.1002/jsfa.11101

35. Singleton, V.L., Orthofer, R., Lamuela-Raventós, R.M. (1999). Analysis of total phenols and other oxidation substrates and antioxidants by means of Folin-Ciocalteu reagent. Methods in Enzymology, 299, 152-178.

https://doi.org/10.1016/S0076-6879(99)99017-1

36. Skinner, R.C., Gigliotti, J.C., Ku, K.M., Tou, J.C. (2018). A comprehensive analysis of the composition, health benefits, and safety of apple pomace. Nutrition Reviews, 76(12), 893-909.

https://doi.org/10.1093/nutrit/nuy033

37. Suárez, B., Álvarez, Á.L., García, Y.D., del Barrio, G., Lobo, A.P., Parra, F. (2010). Phenolic profiles, antioxidant activity and in vitro antiviral properties of apple pomace. Food Chemistry, 120(1), 339-342.

https://doi.org/10.1016/j.foodchem.2009.09.073 
38. Tarko, T., Duda-Chodak, A., Bebak, A. (2012). Biological activity of selected fruit and vegetable pomaces. Żywność. Nauka. Technologia. Jakość, 19(4), 55-65 (in Polish; English abstract).

39. Tsami, E., Krokida, M.K., Drouzas, A.E. (1998). Effect of drying method on the sorption characteristics of model fruit powders. Journal of Food Engineering, 38(4), 381-392.

https://doi.org/10.1016/S0260-8774(98)00130-7

40. van Kleef, E., Otten, K., van Trijp, H.C. (2012). Healthy snacks at the checkout counter: A lab and field study on the impact of shelf arrangement and assortment structure on consumer choices. BMC Public Health, 12(1), art. no. 1072.

https://doi.org/10.1186/1471-2458-12-1072
41. Voda, A., Homan, N., Witek, M., Duijster, A., van Dalen, G., van der Sman, R., Nijsse, J., van Vliet, L., Van As, H., van Duynhoven, J. (2012). The impact of freeze-drying on microstructure and rehydration properties of carrot. Food Research International, 49(2), 687-693.

https://doi.org/10.1016/j.foodres.2012.08.019

42. Wichrowska, D., Żary-Sikorska, E. (2015). Health-promoting properties of apple press pomace. Inżynieria i Aparatura Chemiczna, 54(5), 286-287 (in Polish).

43. Zalewska, M., Otreszko-Arski, A., Zalewski, M. (2016). The influence of convective drying and freeze drying on the colour of selected fruits. Aparatura Badawcza i Dydaktyczna, 21, 141-145 (in Polish). 
